\title{
Defining leadership roles in the academic context: A Nursing Deans' Perspective
}

\author{
Dr. Farhan Alshammari \\ University of Hail, College of Nursing \\ Baqaa Road, Hail City, Hail, Kingdom of Saudi Arabia
}

\begin{abstract}
Albeit research on leadership styles of the educational leaders over the years, most had been westernized than in developing countries. As such, there is still a dearth of the literature of leadership styles of the managers in the universities especially localizing the study on the Deans of the College of Nursing in the Kingdom of Saudi Arabia. This study aims to determine the multifactor leadership styles of the Nursing Deans relating to demographics such as gender, age, years of experience, and the country they graduated from. This study employed quantitative correlational where total population of nursing deans was utilized. The researcher used the Multifactor Leadership Questionnaire Form 6-S (MLQ- 6S), with permission. Data analyses were performed using the statistical software, SPSS version 22.0. The results demonstrated that Nursing Deans employed transactional leadership styles (9.71). The data suggests that there is no significant difference in the leadership styles of the nursing deans as to gender( $P>.05)$. Also, age, years of experience and country they graduated from (highest educational attainment) show no significant difference since all F-values were greater than the 0.05 level of significance. Regardless of age, gender, years of experience and country where they graduated from, the Dean of the College of Nursing can give positively impact the quality of education and eventually improve organizational outcomes.
\end{abstract}

Keywords: laissez-faire, leadership styles, Nursing Deans, Multifactor Leadership, transactional, transformational

\section{INTRODUCTION}

The individual's performance within the organizational workplace is exceedingly affected by the leadership styles of its managers. [1] Indeed, the success of an organization is mostly dependent on its leaders that catalyze innovation. Leaders needed to influence, inspire, and acknowledge their subordinates to carry out and realized the planned outcomes. [2] Undoubtedly, the realization has to start with self to drive more followers towards innovation and excellence. In the academic context, deans as a leader play a significant role to mobilize the subordinates down to the student's level and to meet the expectation required of them. Indeed, research after research has shown that leaders in the academe have always been the driver to raise the student achievement, [3] and the kind of leadership styles of the Deans impact significant job satisfaction. Such leadership retains faculty members that have a substantial role in the success of higher education institutions. It is therefore expected that realization may transcend the success of every student through the leadership of the Deans of the College of Nursing.

Albeit research on the academic leadership styles in the past, leadership studies had been most researched in the western than in developing countries. [4] The literature shows that there is a dearth of studies of leadership styles of the managers in the universities. [5] In fact, the academic deanship had been understudied and most misconstrued position in the educational 
environment. [6] Undeniably, there are contrasting obligations of the Deans and more has shifted towards administrative duties. Based on the searched literature, researchers show how leadership behaviors influence employees to meet better organizational outcomes. From the operational standpoint, it is essential that Deans understand how their leadership decisions affect subordinate's satisfaction that affects outcomes. Kelly [7] pointed out that leadership of the Deans similarly affects learners as scholars, self-improvement, professional advancement, and an extensive variety of the learning results.

Research substantiates on the available literature of leadership behavior practiced by the leaders of the organizations. This perceives leadership styles may have a domino effect on employees' contentment vis-à-vis with the needs of the students. The faculty members tend to look up to the managers of the departments as role models. From an administrative perspective, the Deans provide educators with direction on how to work with them, and this may lead to the success or failure of the organization. Henceforth, this research is significant as it assists the Deans of the College of Nursing to acquire the awareness of their leadership styles as a step toward becoming effective academic, professional leaders. This study aims to determine the multifactor leadership styles of the Nursing Deans of the College of Nursing in the Kingdom of Saudi Arabia. Specifically, it sought to determine the leadership styles of the Nursing Dean, and the relationship of demographic profiles of the Nursing Deans to their leadership styles.

\section{REVIEW OF LITERATURE}

In any venture, leadership has the crucial part in the outcome. The determination of a leadership style is paramount because it can lead the organization to be more efficient. The outcomes of the leadership can enhance the organization's performance because it is perceived as vital driving forces for the company. [9] Indeed, the success or failure of institutions, state, and community can be attributed to the leadership style of a leader. [10] It is in this context that nurses who are mindful of leadership styles support organized working environment [11] much in the sense that they play a vital role towards success.

In an educational standpoint, nursing academic leadership is complex. According to Solman, [12] leaders have to strategize and see things in advance to mitigate risk. This demands collaboration and coordination to conglomerate process and outcomes focused orientation. On the other hand, Dahshan et al., [13] pointed about challenges of nursing leaders such as new roles, new technology, financial constraints, and greater emphasis on participation, cultural diversity, and education. Such grounds made Vesterinen et al., [14]determined that nurse leader who can see their behavior and consider its effects on employees can adjust to a better leadership style. In the higher education studies, the deanship is an under-investigated topic, although the number of deanship studies is growing. [15] The Deans have been described as the "unsung professionals of the academy" because their contributions were "rarely recognized." [16] As a manager, strategic leader and as a scholar, a dean is expected to focus on the detail of daily operations, to act as a visionary by setting long-term goals and plans for the faculty and be engaged in both research and teaching. [17] Scholars showed that the results on leadership styles have a significant relationship with the organizational performance and this may have positive correlation or negative correlation. [18]

The transformational leadership is a process in which "leaders and followers raise one another to higher levels of motivation and morality." [13] Through inspiring, a change process happens and subordinates become encouraged in achieving organizational goals and aims. [19] Transformational leaders transform the beliefs and attitudes of followers to unite and direct followers towards the accomplishment of greater organizational success. [20] In this 
leadership style, the leaders tend to place followers' needs over their own needs often transcending short-term goals by focusing on higher order intrinsic needs. [21] Generally speaking, transformational leaders aim to motivate employees by inspiring them and providing them with individual attention, while also stimulating their intellectual needs. Another useful style of leadership is transactional. The transactional leadership is based on the exchange process that involves fulfilling contractual obligations, setting goals and monitoring and controlling outcomes [10] It involves an exchange process between the leader and the followers, intended to increase followers' compliance with the leader and to the organizational rules. [22] In the long run, transactional leaders specify tasks, monitor performance, and seek to make the desired outcome by providing reward system.

On the other hand, the laissez-faire leadership involves remaining aloof from the responsibilities of leadership, instead of leading from a distance. Chaudhry and Javed [23] justified that Laissez-Faire style is not a critical style that boosts the motivation level of workers as compared to other leadership styles. Laissez-faire leaders allow their subordinates decisions about the work, to do the job in their way and are also responsible for their choice. Sometimes laissez-faire leaders offer subordinates with important material and avoiding feedback. Turrin [24] concluded that the need for nursing school leaders, administrators, and other healthcare institutions to carefully test their leadership practices and the interactions they have with employees. Leaders should strive to support staff about flexible scheduling, autonomy, and professional growth opportunities nursing academic leaders are required to understand how their leadership styles are perceived by the faculty, and how varying leadership styles affect faculty job satisfaction level.

\section{Design}

\section{METHODS}

This study utilized descriptive quantitative- correlational approach and is aimed at determining the leadership styles of the Dean of the College of Nursing at the Kingdom of Saudi Arabia. In this way, it can be measured and objectively analyze for further intellectual pursuits.

\section{Sample and Setting}

The samples of this study are the 20 Deans from the College of Nursing of the Kingdom of Saudi Arabia. Total enumeration has been considered as there is less College of Nursing in the Kingdom of Saudi Arabia, thus to represents the populace.

\section{Instrument}

The researcher used the Multifactor Leadership Questionnaire, Form 6-S (MLQ- 6S) by Bass and Avolio. [25] It has 21-item questions with 5 Likert scale from 0-4 which assesses the leadership style on seven factors embedded in the Transformational, Transactional and Laissez-faire. According to Avolio and Bass [26], the Transformational Leadership comprises the Factor 1(Idealized influence) which covers Item 1, 8 and 15. The inspirational motivation or Factor 2 involves item 2, 9 and 16. Moreover, the Factor 3 or Intellectual stimulation includes Item 3, 10 and 17 while factor 4 or Individualized consideration covers the Items 4, 11 and 18. For the Transactional Leadership, it involves factor 5 or Contingent reward; this includes Item 5, 12 and 19. Lastly, the Laissez Faire covers Factor 6 or Management-ByException Passive (MBEP), and this includes Item 6, 13 and 20, and Factor 7 or Laissez-faire which comprises Items 7, 14 and 21.

To determine the leadership styles of the Nursing Deans, the researcher added the three rating of the items specified which equal to a factor. According to Munaf [27], the summated scores of factor 1, 2, 3 and 4 is equal to the total score of Transformational Leadership divided into 
four (4) to get the composite average score of Transformational Leadership. On the other hand, the summated score of factor 5 is equal to the total score of Transactional Leadership to be divided into one (1). Lastly, the score of factor 6 and 7 will be added to get a total score of Passive /Avoidant Behavior divided into two (2) to get the Composite average score.

\section{Ethical Considerations}

This research has with permission of the authorities of nursing deans in the Kingdom of Saudi Arabia and approved by the independent review board of the Hail Region.

\section{Data Collection}

Data gathering was carried out in October 2016 until February 2017. The researcher provided adequate information, such as the aim of the study, their expected participation, the time required for participation, their right to refuse participation or stop their participation for any reason without any consequences to their part.

\section{Data Analysis}

Data analyses were performed using the statistical software, SPSS version 22.0. Descriptive statistics were used to fully describe the demographic characteristics and the leadership styles of the Nursing Deans. One-way ANOVA was used to look at the differences in the demographic characteristics and the multifactor styles of the samples. The T-test was used when examining the leadership styles of the Nursing Deans regarding gender. All statistical analyses were performed at 0.05 level of significance.

\section{RESULTS}

Table 1 shows the demographic profile of the respondents as to age, gender, years of experience as a dean and the country they graduated from their highest educational attainment. The age groups differed between the respondents, with most deans in the 41-45 year age bracket (45\%), while the least number is above 50 age bracket $(10 \%)$. The rests were $36-40$ at $25 \%$ and $46-50$ at $4 \%$. As gender regards, there were more males (55\%) than females (45\%).Regarding the number of years of overall work experience as a dean, there is a slight variation where most of the deans had above 7 years of work experience $(40 \%) ; 30 \%$ had 4-7 work experience and another $30 \%$ with 0-3 years of work experience. The deans were relatively diverse regarding their country graduated from their highest educational attainment composition. However, a real proportion of the respondents were United Kingdom graduates (30\%). The United States of America graduates had a percentage 25, Kingdom of Saudi Arabia has 20\%; Australia has 15\%, and Others (10\%). 
Table 1. Demographic Profile of the Respondents

\begin{tabular}{lcc}
\hline & Frequency & Percent \\
\hline Age & 5 & \\
36 to 40 & 9 & 25 \\
41 to 45 & 4 & 45 \\
46 to 50 & 2 & 20 \\
above 50 & 20 & 10 \\
Total & & 100.0 \\
Gender & 11 & 55 \\
Male & 9 & 45 \\
Female & 20 & 100 \\
Total & & \\
Years of Experience as a Dean & 7 & 35 \\
0 to 3 & 6 & 30 \\
4 to 7 & 7 & 35 \\
above 7 & 20 & 100 \\
Total & & \\
Country Graduated from their & & 25 \\
Highest Educational Attainment & 5 & 25 \\
KSA & 5 & 25 \\
USA & 5 & 15 \\
UK & 3 & 10 \\
AUS & 2 & 100 \\
Others & 20 & \\
Total & & \\
\hline
\end{tabular}

Table 2 displays the rating of the Nursing Deans per item on the multifactor leadership vis-àvis with its corresponding factor. It shows that the highest item so far is item 6 which states "I am satisfied when others meet agreed-upon standards" having 3.65 average rating under factor 6 or Laissez Faire. The next highest score is item 1 which states, "I make others feel good to be around me" with a rating of 3.59 under factor 1 (Transformational), this followed by item 4 which states "I help others develop themselves" with a rating of 3.47 (Transactional) and the least so far is item 14 which states "Whatever others want to do is OK with me" with a rating of 1.29 under factor 7 (Laissez Faire).

Table 2. Multi-Factor Leadership

\begin{tabular}{llll}
\hline \multicolumn{1}{c}{ Statement } & $\begin{array}{c}\text { Ave. } \\
\text { Rating }\end{array}$ & Rank & Factor \\
\hline 1. I make others feel good to be around me. & 3.59 & 2 & 1 \\
2. I express with a few simple words what we could and should do. & 3.41 & 4.5 & 2 \\
3. I enable others to think about old problems in new ways. & 3.29 & 7.5 & 3 \\
4. I help others develop themselves. & 3.47 & 3 & 4 \\
5. I tell others what to do if they wan t to be rewarded for their work. & 3.06 & 13.5 & 5 \\
6. I am satisfied when others meet agreed-upon standards. & 3.65 & 1 & 6 \\
7. I am content to let others continue working in the same ways always. & 2.65 & 18 & 7 \\
8. Others have complete faith in me. & 3.29 & 7.5 & 1 \\
9. I provide appealing images about what we can do. & 3.12 & 12 & 2 \\
10. I provide others with new ways of looking at puzzling things. & 3.06 & 13.5 & 3 \\
11. I let others know how I think they are doing. & 3.24 & 9.5 & 4 \\
12. I provide recognition/rewards when others reach their goals. & 3.41 & 4.5 & 5 \\
13. As long as things are working, I do not try to change anything. & 2.18 & 19 & 6 \\
14. Whatever others want to do is OK with me. & 1.29 & 21 & 7 \\
15. Others are proud to be associated with me. & 2.94 & 17 & 1 \\
16. I help others find meaning in their work. & 3.25 & 6 & 2 \\
17. I get others to rethink ideas that they had never questioned before. & 2.88 & 15.5 \\
18. I give personal attention to others who seem rejected. & 2.88 & 15.5 & 3 \\
19. I call attention to what others can get for what they accomplish. & 3.24 & 9.5 & 4 \\
20. I tell others the standards they have to know to carry out their work. & 3.18 & 11 & 5 \\
21. I ask no more of others than what is absolutely essential. & 2.12 & 20 & 6
\end{tabular}


Table 3 demonstrates the leadership style of the Nursing Deans. It can be viewed that the Nursing Deans of the Kingdom of Saudi Arabia employed transactional leadership style having 9.71 average scores, followed by transformational leadership with 9.63 average scores. The least leadership style employed was the laissez-faire with an average score of 7.53.

Table 3. Leadership Styles of the Nursing Deans

\begin{tabular}{|c|c|c|}
\hline Leadership Styles & Factor & Average Score \\
\hline Transformational & Factor 1 Idealized Influence ( 1,8 \& 15) & 9.63 \\
\hline & Factor 2 Inspirational motivation( $2,9 \& 16)$ & \\
\hline & Factor 3 Intellectual stimulation(3,10 \& 17) & \\
\hline & Factor 4 Individualized consideration (Items 4,11 \& 18) & \\
\hline Transactional & Factor 5 Contingent reward $(5,12 \& 19)$ & 9.71 \\
\hline Laissez Faire & $\begin{array}{l}\text { Factor } 6 \text { Management-By-Exception Passive (MBEP) }(6,13 \& \\
\text { 20) } \\
\text { Laissez-faire }(7,14 \& 21)\end{array}$ & 7.53 \\
\hline
\end{tabular}

Table 4 demonstrates the difference in the leadership styles of the Nursing Deans regarding their gender. The T-test was used when examining the leadership styles of the Nursing Deans regarding their gender. As seen in the table (Table 2), the yielded t-value of Transformational Leadership is -2.047; Transactional Leadership is -.682, and Laissez-faire Leadership is -1.788. These results yielded a higher value than the .05 level of significance, hence, no significant difference in the leadership style regarding gender.

Table 4. The relationship of age of the Nursing Deans to their Leadership Styles

Leadership Styles

Transformational Leadership

Transactional Leadership

Laissez-faire Leadership t-test for Equality of Means

\begin{tabular}{ccc}
\hline $\mathrm{t}$ & $\mathrm{df}$ & Sig. (2-tailed) \\
$-2.047 \mathrm{NS}$ & 15 & .059 \\
$-.682 \mathrm{NS}$ & 15 & .506 \\
$-1.788 \mathrm{NS}$ & 15 & .094 \\
\hline
\end{tabular}

ANOVA was used when examining the difference of leadership styles of the Nursing Deans terms of their age, years of experience and country graduated from their highest educational attainment (Table 5).

Table 5. Difference of leadership styles as to age, years of experience and country graduated.

\begin{tabular}{|c|c|c|c|c|c|c|}
\hline \multirow[t]{2}{*}{ Leadership Style } & \multicolumn{2}{|l|}{ Age } & \multicolumn{2}{|c|}{ Years of Experience } & \multicolumn{2}{|c|}{ Country Graduated from } \\
\hline & $\mathbf{F}$ & Sig. & $\mathbf{F}$ & Sig. & $\mathbf{F}$ & Sig. \\
\hline $\begin{array}{l}\text { Transformational } \\
\text { Leadership }\end{array}$ & 1.511 NS & .258 & $.127^{\mathrm{NS}}$ & .882 & $.438^{\mathrm{NS}}$ & .779 \\
\hline $\begin{array}{l}\text { Transactional } \\
\text { Leadership }\end{array}$ & $1.304 \mathrm{NS}$ & .315 & $.088 \mathrm{NS}$ & .916 & $.558 \mathrm{NS}$ & .697 \\
\hline $\begin{array}{l}\text { Laissez-faire } \\
\text { Leadership }\end{array}$ & $.804 \mathrm{NS}$ & .513 & 1.474 NS & .262 & 2.145 NS & .138 \\
\hline
\end{tabular}

As reflected in the table, the yielded F-value of Transformational Leadership is 1.511; for Transactional Leadership is 1.304 and for Laissez-faire Leadership is .804. Since all the Fvalues were greater than the 0.05 level of significance, this means that there was no significant difference in the leadership styles of the Nursing Deans terms of their age. As regards years of experience, the yielded F-value of Transformational Leadership is 127; for Transactional Leadership is .088 and for Laissez-faire Leadership is 1.474. Since all the F-values were greater than the 0.05 level of significance, this means that there was no significant difference in the leadership styles of the Nursing Deans terms of their years of experience as a dean. This can be deduced that the leadership styles do not vary according to their years of experience as a dean. 
Concerning the country graduated from their highest educational attainment, the yielded Fvalue of Transformational Leadership is 438; for Transactional Leadership is .558 and for Laissez-faire Leadership is2.145. Since all the F-values were greater than the 0.05 level of significance, this means that there was no significant difference in the leadership styles of the Nursing Deans terms of the country graduated from their highest educational attainment.

\section{Leadership Styles}

\section{DISCUSSION}

The highest rating of the Nursing Deans under factor 6 (Management-By-Exception Passive (MBEP) implies that they have the confidence to their employees to do their assigned responsibilities. The results showed that the Nursing Deans of the Kingdom of Saudi Arabia employed transactional leadership and transformational over laissez-faire. This result may be attributed to the fact that Nursing Deans have been dealing with the employees from various nationalities with different behavior and culture. This finding is in similar to the result of the study of Alshahrani and Baig [20] where they noted that most of the head nurses employed transaction leadership style in combination with transformational leadership. Also, congruent results were in line with the studies of Rehman et al., [28] Lotfiet al, [29] and Marmaya et al. [30] as they indicated that transformational and transactional leadership styles have a positive relationship with employees' organizational commitment. In the study of Alshammari [1], it also stipulates that transformational leadership styles are the best predictors of leadership effectiveness and job satisfaction. As implied in Keskes [22] research, successful leaders should use in both transformational and transactional comportments.

The Nursing Deans of the Kingdom of Saudi Arabia used transactional leadership followed by transformational and lastly, laissez-faire leadership. This finding may be associated with the aspect that Nursing Deans act as mentors, coordinators, facilitators, and innovators to the nursing faculty. The results of this study confirmed with recent researches. Lorber et al. [31] who articulated that leaders most widely use the transactional leadership style. Conversely, Alshahraniand Baig [20] study exhibited that most of the head nurses established transactional leadership style compared to the transformational style of leadership. Marmaya et al., [30] also argued that the relationship between employee commitment and transactional leadership is more significant than transformational leadership style. Likewise, these results were in line with the study of Wu [32] who declared that transactional command is more efficient than transformational leadership style to do organizational goals. Contrariwise, the findings of this research oppose the studies of Dahshan et al. [13] Ahmad et al. [33]

\section{Differences in the leadership styles of the Nursing Deans}

The non-significant relationship as regards gender implies that there is an equal perception of Deans of the College of Nursing that men and women are to be valued as leaders whether what type of leadership they carry out. One potential reason for these results might be the changed roles and characteristics of women as Deans of College of Nursing in the Kingdom of Saudi Arabia. Jonsen et al. [34] implied that there is a clear trend in increasing similarities in the styles of men and women as a result of the changed roles and self-perceptions of women in industrialized countries and the appearance of women in formerly all-male occupations. In the study of Al-Maqbali [35], both men and women have similar views on both leadership behaviors and outcomes. However, in earlier research[36] in the different management levels, it has found that male leaders used inspirational motivation, particularly at the executive level. Nevertheless, to this end, researchers have shown that gender has no direct impact on the leadership styles between men and women and those differences are slowly vanishing. 
The non-significant difference in the leadership styles of the Nursing Deans regarding their age inferred; further, that leadership styles do not vary. Previous research [37] explained that the intention of older workers do not necessarily make decisions with their colleagues as they can draw on their years of experience to make arrangements with a higher degree of confidence, which younger workers usually do not have. Although the age of the Deans may somehow influence people's values, wants, and needs, these study results suggest that this factor is not connected with the leadership style used, but presumably more with different expectations and motivation in the workplace.

The leadership styles do not vary according to the years of experience as a dean.

Study of Al-Maqbali [35] found that there is no significant relationship between total years of experience and faculty members' perceptions about leadership outcomes. The study of File and Shibeshi [38] denote that there is no significant difference between department heads having different work experience in their current position about their perception about their leadership style. Notwithstanding the fact that years of experience does not influence leadership styles, Deans ought to show practices that advance the development of mutual trust, respect, and competence. This will build the credibility and authority of the Deans and give inspirational and normative behavior. Although not all Deans can be expected to have charismatic personalities, the Deans ought to urge followers to regard and appreciate their leaders as role models and valued advocates. In this way, universities should recruit and promote nurse managers who are likely going to be more compelling in imparting shared mission, vision, and qualities as rules for accomplishing authoritative goals and not just given their times of involvement.

The leadership styles of the Nursing Deans regarding the country they graduated from their highest educational attainment show no significant difference. The result can be inferred, that the leadership styles do not vary according to their country of origin. The results suggest that the Deans in Saudi Arabia can effectually manage culturally diverse groups. The findings have real inferences for managing the culturally diverse nursing universities of Saudi Arabia. Therefore, Deans should adopt a supportive leadership style toward employees from a different national culture. Past research [40] concluded that supportive leadership is the leadership style between managers and employees from various national cultures. The Deans, therefore, should be particularly considerate when interacting with employees from a different national culture.

\section{STUDY LIMITATION}

The research was conducted in a wider locality but involves small population. This research involved the Deans of the College of Nursing in the Kingdom of Saudi Arabia which focus to only one respondent per institution, and it might affect the generalization of the study. Therefore, to generalize the results for a larger group, the study should have involved vice dean and department heads.

\section{CONCLUSION}

The leadership styles of the Nursing Deans of the College of Nursing in the Kingdom of Saudi Arabia can impact the outcome of the effectiveness of the faculty members. Defining own leadership styles and its affecting variables such as age, gender, years of employment, and the country they graduated would lead to awareness of how leadership styles play in the organization. Exploring and understanding own leadership style enhances enthusiasm towards goal achievement, and this can be translated to the future nurses who can be a powerful force for shaping education and health policy. 


\section{References}

Alshammari, F. Nursing Leadership in the Ministry of Health Hospitals of Saudi Arabia[Internet] 2014 [ cited 2017 Jan 9]. Available from https://researchbank.rmit.edu.au/eserv/rmit:160740/Alshammari.pdf. (accessed 11=January 2017).2014

Andersen, J. A., An Old Man and The "Sea of Leadership." JLS[Internet]. 2016[cited 201 Jun 20]; 9 (4): 70-81. Available from http://onlinelibrary.wiley.com/doi/10.1002/jls.21422/abstract

Goodwin, B., Milk, K. Research says for positive behavior, involve peers. EEL[Internet] 2012[cited 2017 Jan 4]. Available from http: / www.ASCD.org.

Shah, S. Re-thinking educational leadership: Exploring the impact of cultural and belief systems. IJLE. 2010; 13:27-44.

Wirbaa, A., Shmailan, A. Leadership styles of managers in Universities in Saudi Arabia. MRJ ERev .2015. 3:174-184.

Otara, A. Academic Dean and the challenges of meeting changing expectations within a competitive higher education environment in Africa. $\mathrm{Cr}$ Ed.[Internet] 2015; 6: 134-143. Available from http://dx.doi.org./10.4236.2015.62012.

Kelly, R. Implementing High-Impact Learning across the Institution. AL[Internet] 2012[cited 2016 Dec.2]. Available from https://www.facultyfocus.com/articles/academic-leadership/implementing-high-impactlearning-across-the-institution/

Wahab, S., Rahmat, A., Yusof, M., Mohamed, B. Organization performance and leadership style: Issues in Education Service. Procedia - S BSci. 2016; 224:593-598.

Obiwuru, T .C., Okwu, A.T., Akpa, V.O., \& Nwankwere, I.A. Effects of leadership style on organizational performance: A survey of selected small-scale enterprises in Ikosi-Ketu Council Development area of Lagos State, Nigeria. AJBMRes. 2011; 1:7, 100-111

Oladipo K. S., Jamilah O., Abduldaud S., Jeffery L. D. and Salami D. K., Review of leadership theories and Organizational performances. IBMjrn. 2013; 7: 50-54.

Cope, V., Murray, M. Leadership styles in nursing. Nsg.Std. 2017; 31:43

Solman, A. Ideas, and Influences. What is the place of interprofessional education in supporting the continuum of care for patients? IPDJ.2016; 6 (1), 1-2.

Dahshan, D., Youssef, D., Aljouaid, M., Babkeir, R. Hassan, D. Effect of nurse managers' leadership styles on organizational commitment of nurses working at Taif governmental hospitals in Kingdom of Saudi Arabia. JNHSci. 2017; 6(2), 35-46.

Vesterinen, S., Suhonen, M., Isola, A. Paasivaara, L. Nurse Managers' Leadership Styles in Finland. NRPract.[Internet] 2016[cited 2017 Jun 10]. Available from http://dx.doi.org/10.1155/2012/605379

Nguyen, T.L.H. Middle-level Academic Management: A case study on the roles of the Heads of Department at a Vietnamese university.TEM.2013; 19(1), 1-15.

De Boer, H., \& Goedegebuure, L. The Changing Nature of the Academic Deanship. Leadership 2009; 5(3), 347-364.

Ngo, J., de Boer, H., Enders, J. The way deans run their faculties in Indonesian universities. TEM. 2013; 20(1), 1-13.

Wang, F.J., Shieh, C.J., Tang, M.L. Effect of Leadership Style on Organisational Performance as Viewed from Human Resource Management Strategy. AJBM.2010; 14(18), 3924-3936.

Foon, M.S. A Conceptual Framework of Transformational and Transactional Leadership on Nurse Educators Job Satisfaction. IJSSHRes.2016; 4 (1): 596-605.

Alshahrani, F. M., Baig, L. A. Effect of Leadership Styles on Job Satisfaction Among Critical Care Nurses in Aseer, Saudi Arabia. Journal of the College of Physicians and Surgeons Pakistan 2016; 26 (5): 366-370.

Kuria, L.K., Namusonge, G. S., Iravo, M. Effect of Leadership on Organizational Performance in Health Sector. IJSRPub. 2016; 6 (7): 658-663.

Keskes, I. Relationship between Leadership Styles and Dimensions of Employee Organizational Commitment: A Critical Review and Discussion of Future Directions. IC. 2014; 10(1): 26-51.

Chaudhry, A., Javed, H. Impact of transactional and laissez-faire leadership style on motivation. IJBSS.2012; 3 (7).

Turrin, C. The Influence of Nursing Academic Leadership on Faculty Retention. Ph.D. Walden University. 2016. Available from http://scholarworks.waldenu.edu/dissertations/3011/ 
Bass, B. M., Avolio, B. J. MLQ Multifactor Leadership Questionnaire Redwood City: Mind Garden.1992

Avolio, B.J., Bass, B.M. Multifactor Leadership Questionnaire. Mind Garden, Inc.2004;4, 17

Munaf, S. Teachers' quality performance as a function of management style in higher education. Working Paper No. 11.2016

Rehman, S., Shareef, A., Mahmood, A., and Ishaque, A. Perceived Leadership Styles and Organizational Commitment. Interdisciplinary Journal of Contemporary Research in Business 2012;4(1): 616-626.

Lotfi, F., Mokhtarpour, S., Momenirad, A., Amini, M. and Kojuri, J. (2012). Relevance Between Leadership Style and Organizational Commitment of Faculty Members. Medical Journal of Hormozgan University; 16 (3): $233-239$.

Marmaya, N. H., Hitman, M., Torsiman, N. N., Balakrishnan, B. Employee’s Perception of Malaysian Managers' Leadership Styles and Organizational Commitment. African Journal of Business Management 2011; 5(5): 15841588.

Lorber, M., Treven, S., Mumel, D. The Examination of Factors Relating to the Leadership Style of Nursing Leaders in Hospitals. Nase gospodarstvo 2016; 62(1): 27-36.

Wu, F. The Relationship between Leadership Styles and Foreign English Teachers Job Satisfaction in Adult English Cram Schools: Evidence in Taiwan. The Journal of American Academy of Business, Cambridge 2009; 14(2): 18-25.

Ahmad, A., Abdul Majid, A., Zin, M. The Measurement of the Effectiveness of Leadership Styles for Organizational Commitment in Pakistan. Asian Social Science 2015; 11(25): 135-143.

Jonsen, K., Maznevski, M. L., Schneider, S. C. Gender differences in leadership-Believing is seeing: Implications for managing diversity. Equality, Diversity and Inclusion: AJ[internet]2010[cited 3 Feb 2017] 29(6), 549-572.

Available from http://dx.doi.org/10.1108/02610151011067504.

Al-Maqbali, F., Hamood Ali."The Impact of the Leadership Styles of Deans on the Faculty Members' Level of Job Satisfaction in Nursing Education in Oman".Ph.D. University of Glasgow, 2017.

Vinkenburg, C. J., van Engen, M. L., Eagly, A. H., Johannesen-Schmidt, M. C. An exploration of stereotypical beliefs about leadership styles: Is transformational leadership a route to women's promotion? The Leadership Quarterly 2011;22(1), 10-21.

Ekaterini, G. The impact of leadership styles on four variables of executives' workforce. International Journal of Business and Management 2010; 5(6), 3-16.

File, G., Shibeshi, A. Department Heads' Self-Perception of their Leadership Styles at Jimma University, Ethiopia. Ethiop. J. \& Sc. 2012; (7), 2,97-114

Kim, Y., Hancer, M.Leadership Style and National Culture on Restaurant Employees' Affective Commitment. Oklahoma.2011. Available from http://scholarworks.umass.edu/cgi/viewcontent.cgi?article=1135\&context=gradconf

Hospitality. 